\title{
Inactivation of the Glial Fibrillary Acidic Protein Gene, But Not That of Vimentin, Improves Neuronal Survival and Neurite Growth by Modifying Adhesion Molecule Expression
}

\author{
Véronique Menet, ${ }^{1}$ Minerva Giménez y Ribotta, ${ }^{1}$ Norbert Chauvet, ${ }^{1}$ Marie Jeanne Drian, ${ }^{1}$ Julie Lannoy, ${ }^{1}$ \\ Emma Colucci-Guyon, ${ }^{2}$ and Alain Privat ${ }^{1}$ \\ ${ }^{1}$ Institut National de la Santé et de la Recherche Médicale U336, Université Montpellier II, F-34095 Montpellier, France, \\ and ${ }^{2}$ Unité de Biologie du Développement, Institut Pasteur, F-75015 Paris, France
}

\begin{abstract}
Intermediate filaments (IFs) are a major component of the cytoskeleton in astrocytes. Their role is far from being completely understood. Immature astrocytes play a major role in neuronal migration and neuritogenesis, and their IFs are mainly composed of vimentin. In mature differentiated astrocytes, vimentin is replaced by the IF protein glial fibrillary acidic protein (GFAP). In response to injury of the CNS in the adult, astrocytes become reactive, upregulate the expression of GFAP, and reexpress vimentin. These modifications contribute to the formation of a glial scar that is obstructive to axonal regeneration. Nevertheless, astrocytes in vitro are considered to be the ideal substratum for the growth of embryonic CNS axons. In the present study, we have examined the potential role of these two major IF proteins in both neuronal survival and neurite growth. For this purpose, we cocultured wild-type neurons on astrocytes from
\end{abstract}

three types of knock-out (KO) mice for GFAP or/and vimentin in a neuron-astrocyte coculture model. We show that the double $\mathrm{KO}$ astrocytes present many features of immaturity and greatly improve survival and neurite growth of cocultured neurons by increasing cell-cell contact and secreting diffusible factors. Moreover, our data suggest that the absence of vimentin is not a key element in the permissivity of the mutant astrocytes. Finally, we show that only the absence of GFAP is associated with an increased expression of some extracellular matrix and adhesion molecules. To conclude, our results suggest that GFAP expression is able to modulate key biochemical properties of astrocytes that are implicated in their permissivity.

Key words: astrocytes; cytoskeleton; intermediate filaments; knock-out mice; extracellular matrix; $N$-cadherin
In the developing CNS of mammals, astrocytes constitute a major substratum for neuronal migration and axon growth (Rakic, 1971). In the injured adult CNS, however, astrocytes are a key component of reactive gliosis (Hatten et al., 1991; Ridet et al., 1997), which is considered to be a major impediment to axonal regeneration (Ramón y Cajal, 1913-1914; Brown and McCough, 1947; Reier et al., 1989). After injury, astrocytes proliferate and become hypertrophic. The hallmark of reactive gliosis is the upregulation of two intermediate filament (IF) proteins, vimentin (Vim) and glial fibrillary acidic protein (GFAP) (Bignami and Dahl, 1976; Dahl et al., 1981b). Recently, it has been demonstrated that nestin, an IF protein predominantly expressed by CNS progenitor cells (Lendahl et al., 1990; Dahlstrand et al., 1995), is also reexpressed in reactive astrocytes (Clarke et al., 1994; Frisen et al., 1995).

The expression of Vim and GFAP is tightly regulated during development (Lazarides, 1982). Vim is expressed in radial glia and immature astrocytes and, during the astrocyte differentiation, is progressively replaced by GFAP (Dahl et al., 1981a; Bignami et

Received March 21, 2001; revised May 17, 2001; accepted May 31, 2001.

This work was supported by the Institut National de la Santé et de la Recherche Médicale, the Institut pour la Recherche sur la Moelle Epinière, Verticale, Centre National pour la Recherche Scientifique, and the Institut Pasteur. We thank M. Saunier and F. Sandillon for technical help and J. R. Teilhac for art work. We also thank Dr. R. D. G. McKay for the gift of the nestin antibody and Dr. C. Babinet for valuable discussion.

Correspondence should be addressed to V. Menet, Institut National de la Santé et de la Recherche Médicale U336, University of Montpellier II, Place Eugène Bataillon, Box 106, F-34095 Montpellier Cedex 05, France. E-mail:

menet@crit.univ-montp2.fr.

Copyright (C) 2001 Society for Neuroscience $\quad 0270-6474 / 01 / 216147-13 \$ 15.00 / 0$ al., 1982), with some exceptions such as Bergmann glia in the cerebellum (Shaw et al., 1981).

In primary cultured astrocytes, the Vim-GFAP transition is incomplete (Bignami and Dahl, 1989). Therefore, Vim is coexpressed with GFAP (Chiu et al., 1981; Ciesielski-Treska et al., 1988) forming copolymers (Abd-el-Basset et al., 1992). Thus, primary cultures of astrocytes are more comparable with reactive astrocytes than with normal astrocytes in vivo (Bignami and Dahl, 1989; Privat et al., 1995). Nevertheless, primary culture of astrocytes has been considered to be the optimal substratum for the growth of embryonic CNS axons (Noble et al., 1984; Tomaselli et al., 1988).

The involvement of GFAP in the formation of astrocytic processes was demonstrated by using antisense inhibition of GFAP expression (Weinstein et al., 1991), thus opening up the possibility of modulating astrogliosis induced by injury (Yu et al., 1991, 1993; Ghirnikar et al., 1994). We have shown previously that the blockage of astrocyte reaction after a spinal cord (SC) lesion via local pharmacological therapy permits some axonal regeneration (Giménez y Ribotta et al., 1995). However, those experimental conditions did not enable us to discern whether the key element was the impediment of astrocyte hypertrophy (correlated with the upregulation of GFAP and Vim) or of astrocyte hyperplasia.

To dissect out this phenomenon, we used here mice deficient in GFAP (Pekny et al., 1995) and/or Vim (Colucci-Guyon et al., 1994). Double KO mice obtained by crossing single mutants, as well as single KO mice lacking GFAP or Vim, seem to develop and reproduce without obvious defects. However, it was shown recently that the astroglial reaction to SC injury was more re- 
stricted in the double KO mice compared with that of wild-type $(+/+)$ mice (Pekny et al., 1999). We have shown recently in a preliminary study the positive influence of the GFAP $-/-$ astrocytes on neuronal survival and neurite growth (Menet et al., 2000). Here, we analyze whether the absence of GFAP or Vim or both made these astrocytes a more favorable substrate for neuronal survival and neurite extension.

We performed two coculture models: (1) a heterotopic coculture associating $+/+$ embryonic neurons from the cortex that were cultured on $+/+$ or mutant (double KO, GFAP-/- or Vim-/-) neonatal SC astrocytes (their target region) and (2) a homotopic coculture model in which $+/+$ neocortical neurons were cultured on $+/+$ or double KO neonatal cortical astrocytes. We show that neuronal survival and neurite growth are significantly improved when neurons were cultured on double $\mathrm{KO}$ astrocytes compared with those growing on $+/+$ astrocytes. Moreover, we show that the absence of Vim is not a key element in the permissivity of the mutant astrocytes. Finally, we show that the sole absence of GFAP leads to an increased expression of some permissive extracellular matrix (ECM) and adhesion molecules.

\section{MATERIALS AND METHODS}

\section{Animals}

Wild-type mice [+/+; genetic background, (C57BL/6*DBA2)F1] were purchased from IFFA Credo (Lyon, France) and from M\&B A/S (Ry, Denmark) [+/+; genetic background, 129/sv]. Because the results obtained with "129/sv" astrocytes were similar to these obtained with mixed background, only the results obtained with the latter are reported.

KO mice for GFAP (Pekny et al., 1995) and Vim (Colucci-Guyon et al., 1994) were crossed to generate double knock-out mice [mixed genetic background (Pekny et al., 1999)], hereafter respectively referred to as GFAP $-/-$, Vim $-/-$, and double KO mice.

\section{Astrocyte monolayers}

Cell cultures. Primary cultures of astrocytes were established from 2- to 3 d-old double KO, GFAP-/-, or Vim $-/-$ mice and from their wildtype counterparts. Animals were aseptically killed. The SC and the cortex were respectively dissected.

After the meninges were removed, SC and cortical pieces were enzymatically treated with a solution of $0.25 \%$ trypsin-EDTA (Life Technologies, Gaithersburg, MD) for $8 \mathrm{~min}$ at $37^{\circ} \mathrm{C}$. Trypsin action was inactivated by the addition of $10 \%$ fetal bovine serum (FBS; Life Technologies). The tissues were then rinsed in HBSS without calcium and magnesium (Life Technologies) and resuspended in $1 \mathrm{ml}$ of the culture medium including a 1:1 mixture of Dulbecco's modified essential medium and Ham's F12 (D/F; Life Technologies) supplemented with 10\% FBS and $6 \% 0$ glucose. Single-cell dissociation was performed with a Pasteur pipette. Dissociated cells were resuspended in the same culture medium and plated at a final concentration of $\sim 200,000$ cells/well $\left(100,000\right.$ cells $\left./ \mathrm{cm}^{2}\right)$, in 24-well multidishes $\left(2 \mathrm{~cm}^{2}\right.$; Nunc, Roskilde, Denmark) on glass coverslips pretreated with $50 \mu \mathrm{g} / \mathrm{ml}$ poly-D-lysine (Sigma, St. Louis, MO).

The culture medium was totally replaced $24 \mathrm{hr}$ later by a cold culture medium and subsequently once a week. In these conditions, astrocyte SC or cortical cultures reached confluence after $15 \mathrm{~d}$ in vitro (DIV).

In some experiments, the medium from double $\mathrm{KO}$ or from $+/+\mathrm{SC}$ astrocytes was collected after 13 DIV and replaced by a culture medium containing the N2-supplement (Life Technologies) in place of FBS. Two days later, this medium was removed and used as a conditioned medium $(\mathrm{CM})$ in the third paradigm.

Immunocytochemical characterization. Wild-type, double KO, GFAP-/-, or Vim $-/$ - astrocyte cultures were fixed at 21 DIV with $4 \%$ paraformaldehyde in $0.1 \mathrm{M}$ phosphate buffer, $\mathrm{pH} 7.4$, for $45 \mathrm{~min}$ at room temperature. The cells were then washed with PBS and processed for immunostaining. They were incubated with mouse monoclonal or rabbit polyclonal antibodies directed against different markers: (1) rabbit polyclonal IgG directed against GFAP (1:10,000; Dako, Glostrup, Denmark) or nestin [1:1500; a gift from R. Mc Kay; Tohyama et al. (1992)] and (2) mouse monoclonal IgG directed against Vim (3B4 clone; 1:100; Dako).
All primary antibodies were diluted in PBS containing 5\% nonspecific goat or rabbit serum in the presence of $0.1-0.5 \%$ Triton X-100.

After $24 \mathrm{hr}$ at $4^{\circ} \mathrm{C}$, the cultures were rinsed in Tris-buffered saline (TBS) and incubated for $1 \mathrm{hr}$ at room temperature with the secondary antibody [goat anti-rabbit (1:200; Sigma) or rabbit anti-mouse $(1: 100$; Sigma) antibodies]. Immunoreactivity was revealed by the peroxidaseantiperoxidase system. The chromogen used for development was $0.1 \%$ $3,3^{\prime}$-diaminobenzidine in the presence of $\mathrm{H}_{2} \mathrm{O}_{2}$. Finally, glass coverslips were mounted in Depex after dehydration and three passages in Bioclear (Bio-optica, Milan, Italy).

Some wells of $+/+$ and double KO, GFAP $-/-$, or Vim-/- SC astrocyte cultures were processed for single or double immunofluorescence. The cultures were incubated with primary antibodies, namely, a mouse monoclonal IgM directed against chondroitin sulfate proteoglycans (CS56; 1:500; Sigma), a rabbit polyclonal IgG directed against laminin (1:500; Sigma), or a rabbit polyclonal IgG directed against fibronectin (1:1000; Chemicon, Temecula, CA). They were incubated for one night at $4^{\circ} \mathrm{C}$ with the antibodies diluted in PBS containing $1 \%$ normal goat serum and $1 \%$ bovine serum albumin in the presence of $0.1 \%$ Triton $\mathrm{X}-100$. After rinsing in PBS, the SC astrocyte cultures were incubated for $2 \mathrm{hr}$ at $4^{\circ} \mathrm{C}$ with two secondary antibodies including indocarbocyanine (Cy3)-conjugated goat anti-mouse IgM (1:800; Jackson ImmunoResearch, West Grove, PA), Alexa-conjugated goat anti-rabbit IgG (1:400; Molecular Probes, Leiden, The Netherlands), or Cy3-conjugated goat anti-rabbit IgG (1:800; Jackson ImmunoResearch). After careful rinsing, glass coverslips were mounted in Mowiol (Calbiochem, La Jolla, CA), and SC astrocyte cultures were observed under a confocal microscope.

Electron microscopy analysis. Wild-type and mutant SC astrocyte cultures were fixed at $15 \mathrm{DIV}$ with $2.5 \%$ glutaraldehyde in $0.1 \mathrm{M}$ phosphate buffer, $\mathrm{pH} 7.4$, for $30 \mathrm{~min}$. The cultures were post-fixed for $30 \mathrm{~min}$ in $1 \%$ osmium tetroxide in $0.1 \mathrm{M}$ phosphate buffer, stained en bloc with uranyl acetate for $3 \mathrm{hr}$, and embedded in Araldite. The ultrathin sections (80 $\mathrm{nm})$ were examined with a Zeiss 900 electron microscope.

Immunoblottings. Wild-type and mutant SC astrocyte cultures were prepared after 15 DIV for immunoblotting. Total proteins from $+/+$ and mutant astrocyte cultures at confluence (15 DIV) were extracted for Western blotting. Briefly, $+/+$ and mutant astrocyte monolayers were washed in PBS, scraped from the dishes in PBS containing a proteinase inhibitor complex (PIC; Roche Diagnostics, Mannheim, Germany), sonicated, and conserved at $-20^{\circ} \mathrm{C}$. Equal loads of samples $(12 \mu \mathrm{g} / \mu \mathrm{l})$ were electrophoresed on a 6.5 or $15 \%$ Tris-HCl SDS-polyacrylamide gel and blotted on a nitrocellulose membrane in transfer buffer. After blocking the membrane with 5\% skimmed milk in TBS-Tween for $1 \mathrm{hr}$ and 30 min, the blots were incubated with the primary antibody: (1) rabbit polyclonal IgG directed against GFAP (1:100,000; Dako) and (2) mouse monoclonal IgG directed against Vim (3B4 clone; 1:100; Dako) for one night at $4^{\circ} \mathrm{C}$. Secondary antibodies were peroxidase-conjugated antirabbit (1:8000) or anti-mouse (1:2000) IgG (Sigma). The binding of antibodies to proteins was visualized by enhanced chemiluminescence using an ECL Western blotting detection kit (Amersham Pharmacia Biotech, Piscataway, NJ).

Extracellular matrix molecules and adhesion molecules were detected in wild-type, GFAP-/-, Vim -/-, and double KO SC astrocyte cultures using (1) rabbit polyclonal IgGs directed against laminin (1:1000; Sigma), fibronectin (1:500; AB1942 clone; Chemicon), and neural-cell adhesion molecule (N-CAM; 1:5000; Chemicon) and (2) mouse monoclonal IgG directed against the N-cadherin (1:2500; Transduction Laboratories, Lexington, KY). The binding of antibodies to proteins was visualized as described above.

\section{Neuron-astrocyte cocultures}

After cultured astrocytes attained confluence, three experimental paradigms were developed.

Embryonic neurons were cocultured directly on the $+1+$ and double KO, GFAP-/-, or Vim -/-SC astrocyte monolayers. A neuronal suspension was prepared from the neocortex of 14-d-old +/+ mice embryos. After the meninges were removed, the tissue was incubated in HBSS without $\mathrm{Ca}^{2+}$ and $\mathrm{Mg}^{2+}$ for $5 \mathrm{~min}$ at $37^{\circ} \mathrm{C}$ and then for $25 \mathrm{~min}$ at room temperature. The cells were then mechanically dissociated in $1 \mathrm{ml}$ of $\mathrm{D} / \mathrm{F}$ supplemented with N2-complement (D/F-N2). The cells were seeded onto the surface of the 2-week-old confluent SC astrocyte monolayers (from $+/+$ or mutant mice) at the initial density of 62,500 cells $/ \mathrm{ml}$ (25,000 cells/well). To compare the properties of astrocytes from different CNS regions, a homotopic coculture model was performed using cortical astrocyte monolayers from $+/+$ and double $\mathrm{KO}$ mice. One-third 
of the medium was replaced every third day by D/F-N2 at room temperature. Cocultures were maintained for $7 \mathrm{~d}$.

Embryonic neurons were placed on microporous membranes and cultured on the $+1+$ or double KO SC astrocyte monolayers. Dissociated $+1+$ cortical neurons were placed, at the same density as above, on microporous membranes $(0.45 \mu \mathrm{m}$ pore size; $10 \mathrm{~mm}$ diameter; Millipore, Bedford, MA) precoated with poly-D-lysine and then cultured on the 2 -week-old $+1+$ or double $\mathrm{KO}$ astrocyte primary cultures. They were maintained in coculture for $7 \mathrm{~d}$.

Embryonic neurons were cocultured in double $\mathrm{KO}$ or $+/+\mathrm{CM}$ on $+/+$ $S C$ astrocyte monolayers. Wild-type cortical neurons were dissociated in a $\mathrm{CM}$ (collected previously from confluent double $\mathrm{KO}$ or $+/+\mathrm{SC}$ astrocytes) and plated, at the same density as above, on the 2-week-old $+/+$ astrocyte monolayers. One-third of the medium was replaced every third day by $\mathrm{CM}$, and cocultures were maintained for $7 \mathrm{~d}$.

\section{Analysis of astrocyte-neuron cocultures}

The neuronal population in the three paradigms of cocultures was characterized by immunocytochemistry. After 7 DIV of coculture, the experimental preparations were fixed with $4 \%$ paraformaldehyde in $0.1 \mathrm{M}$ phosphate buffer. After rinsing in PBS, the preparations were incubated with a mouse monoclonal $\operatorname{IgG}$ antibody directed against the $\beta$-III-tubulin protein (1:500; Sigma) and processed as described above. Immunoreactivity was revealed using the peroxidase-antiperoxidase system, as described above.

Two parameters were evaluated, neuronal density and neurite growth. They were estimated with a SAMBA 2005 computer system. In each paradigm, neuronal density was expressed as a percentage of that for neurons growing on $+/+$ astrocyte monolayers, which was taken as the control. Neurite growth was quantified in two ways: (1) the surface occupied by the perikarya and neurites per neuron was evaluated, and (2) the neurite lengths (micrometers) per neuron were measured. The experiments were performed three to five times. In each experiment, three to five coverslips were used per condition, and five fields per coverslip were randomly selected at a magnification of $450 \times$. Statistical comparisons were performed using the Mann-Whitney $U$ test.

\section{RESULTS}

In this study, we investigated in a neuron-astrocyte coculture model the possible contribution of the two major astrocytic IF proteins (GFAP and Vim) to the support of neuronal survival and neurite outgrowth. We first characterized the double KO cultured astrocytes, and second we analyzed the parameters of neuronal survival and neurite extension using three experimental paradigms of coculture. We then compared in the standard coculture paradigm the Vim $-/-$ and the GFAP $-/-$ astrocytes in their interactions with cocultured neurons, and finally, we analyzed the expression of ECM and adhesion molecules in +/+, Vim-/-, GFAP $-/-$, and double KO primary SC cultured astrocytes.

\section{Characterization of the double $\mathrm{KO}$ astroglial cultures}

Spinal cord glial cultures of wild-type and double KO mice were compared for GFAP-, vimentin-, and nestin-immunostaining patterns (Fig. 1.).

After $21 \mathrm{DIV},>85 \%$ of the cells in $+/+$ cultures were GFAP positive (Fig. $1 A$ ). The majority of the cells were also Vim positive (Fig. $1 B$ ). As expected, double $\mathrm{KO}$ astrocytes were GFAP and Vim immunonegative (Fig. $1 D, E$ ), and this was confirmed by Western blot analysis (data not shown).

To characterize the double mutant astroglial cultures, we used the marker nestin, another IF expressed by cultured astrocytes. As expected, our nestin antibodies decorated a well developed nestin network in $+/+$ astrocytes (Fig. 1C). The number of nestin-positive cells was similar for the double $\mathrm{KO}$ astrocytes, indicating that the double $\mathrm{KO}$ primary cultures consisted of $>85 \%$ astroglial cells. However, the nestin immunostaining was diff usely spread throughout the cytoplasm (Fig. $1 F$ ), indicating that nestin is not organized in a network in these cells. Detection of 2',3'-cyclic nucleotide $3^{\prime}$-phosphodiesterase (CNPase), a marker of oligodendrocytes, evidenced $5-10 \%$ positive cells, in equal numbers and similar morphology in wild-type and double KO (data not shown).

At the ultrastructural level, $+/+$ astrocytes exhibited processes containing bundles of glial filaments (Fig. $2 A$ ). In contrast, the ultrastructural analysis of double $\mathrm{KO}$ astrocyte monolayers showed that their cytoplasm was totally devoid of glial filaments and contained a large number of dense organelles and microtubules (Fig. 2B).

In the same way, after $21 \mathrm{DIV},+/+$ cortical astrocyte cultures consist of $>95 \%$ GFAP-positive cells corresponding to the well defined type- 1 astrocytes. The majority of cells were also nestin positive. As expected, double KO cortical astrocytes were totally devoid of GFAP and Vim, and the immunostaining of nestin was diff usely spread throughout the cytoplasm, as was the case for SC astrocyte cultures. CNPase and ED-1 immunodetections were performed to determine the eventual contamination of our astroglial cultures by oligodendrocytes and microglia, respectively. We only observe a small number of contaminating cells, which represents $<1 \%$ in our cultures for each cell type. No neurons were detected with $\beta$-III-tubulin immunostaining (data not shown). So, cortical primary cultures can be considered as an almost pure astroglial culture. Thus, these two types of primary glial monolayers (SC and cortical cultures) were used to determine the influence of astrocytes on neuronal survival and neurite growth in two models of neuron-astrocyte cocultures (homotopic vs heterotopic cocultures). Moreover, these two types of primary glial monolayers permit us to discriminate the sole role of the astrocytes per se on neuronal survival and neurite growth because the two coculture models contain at least 85 to $>95 \%$ astrocytes.

\section{Neuronal density is increased on double KO astrocytes}

We have shown recently that GFAP-/- astrocytes are a favorable substrate for neuronal survival and neurite growth in a neuron-astrocyte coculture model (Menet et al., 2000). To determine how the absence of the two major IF proteins GFAP and Vim could affect neuronal attachment and survival, embryonic day 14 wild-type neocortical neurons were seeded onto confluent $+/+$ or double KO SC or cortical astrocyte monolayers. Cells positive for $\beta$-III-tubulin were counted after 7 DIV of coculture (Fig. 3). To compare different series of cultures adequately, neuronal density measured on $+/+$ astrocytes was arbitrarily considered as a $100 \%$ standard.

In the first paradigm, when neurons were seeded directly onto the $+/+$ or double KO SC astrocyte monolayers, which consist of $>85 \%$ astrocytes, neuronal density appeared to be significantly $(3 \times)$ higher when $+/+$ neocortical neurons were grown on double $\mathrm{KO}$ astrocyte monolayers, with a mean increase of $357.16 \pm$ $56.9 \%$ in $\beta$-III-tubulin-positive cells (Fig. $3 A 1, p<0.001$ ).

Similarly, when neurons were seeded onto cortical astrocyte monolayers, which consist of $>95 \%$ astrocytes, we found that neuronal density was significantly higher $(2 \times)$ when $+/+$ neocortical neurons were grown on double $\mathrm{KO}$ homotopic astrocyte monolayers, with a mean increase of $206.84 \pm 16.23 \%$ in $\beta$-IIItubulin-positive cells (Fig. $3 A 2, p<0.001$ ).

Interestingly, cultures performed on $+/+$ cortical astrocytes revealed a better survival than for $+/+\mathrm{SC}$ astrocytes, thus confirming the superiority, in this respect, of homotopic cocultures over heterotopic ones (Chamak et al., 1987).

These two experiments, involving primary glial cultures, which 

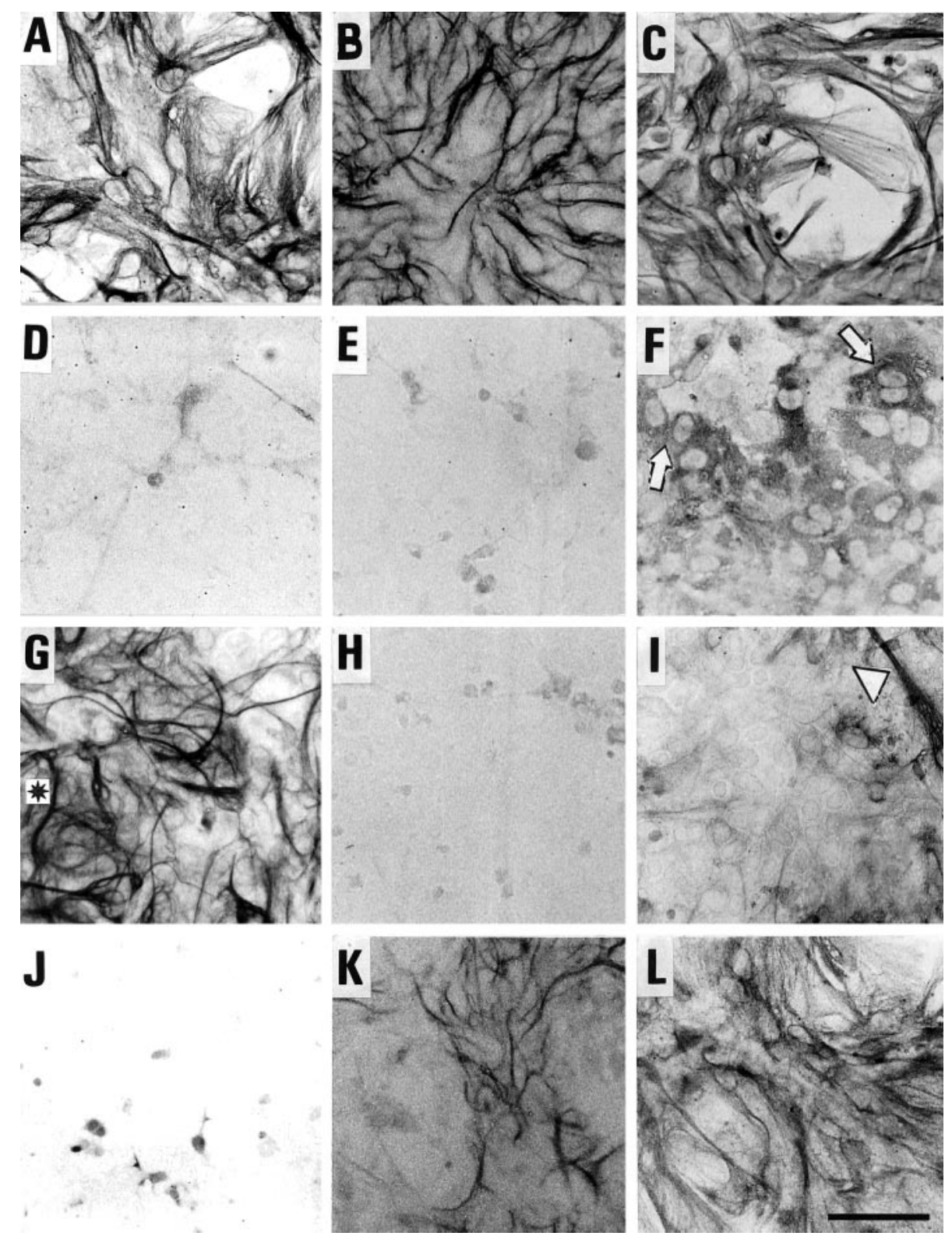

Figure 1. Immunocytochemical characterizaafter 21 DIV from $+/+(A-C)$, double KO $(D-$ $F)$, Vim $-/-(G-I)$, and GFAP $-/-(J-L)$ were immunostained for GFAP $(A, D, G, J)$, vimentin $(B, E, H, K)$, and nestin $(C, F, I, K)$. Vim and GFAP are totally absent in double $\mathrm{KO}$ astrocytes $(D, E)$. Vim or GFAP are respectively absent in Vim $-/$ - or GFAP $-/-$ astrocytes $(H, J)$. Note the tightly packed GFAP filament staining in Vim- - - astrocytes $(G$, asterisk). In contrast, nestin immunostaining is diff use throughout the cytoplasm in double $\mathrm{KO}(F$, arrow) and Vim-lastrocytes $(I)$. Some Vim $-/-$ astrocytes exhibit a nestin polymerized labeling (I, arrowhead) as observed in $+/+$ and GFAP- $/-$ astrocytes $(C$, $L)$. Scale bar, $50 \mu \mathrm{m}$.

contain 85 and $95 \%$ astrocytes, respectively, demonstrate that neuronal survival can be attributed to the properties of astrocytes and not to the influence of eventual contaminating cells in the cultures.

To determine whether the differences in neuronal density observed on double KO SC astrocyte monolayers could be caused by diffusible factors, a second experimental paradigm was performed. Dissociated $+/+$ neocortical neurons were placed on microporous membranes and cultured on the $+/+$ or double $\mathrm{KO}$ $\mathrm{SC}$ astrocyte monolayers. In this situation, neurons and astrocytes did not establish direct contact but only communicated via diffusible factors. $\beta$-III-Tubulin-positive cells growing on microporous membranes were counted after 7 DIV (Fig. $3 B$ ).

When $+/+$ neocortical neurons were growing over double $\mathrm{KO}$ $\mathrm{SC}$ astrocyte monolayers on the microporous membrane, we found that the neuronal density was significantly higher than that of neurons growing over $+/+\mathrm{SC}$ astrocyte monolayers, with a mean increase of $167.52 \pm 14.58 \%$ in $\beta$-III-tubulin-positive cells (Fig. $3 B$, $p<0.001)$. However, this increased percentage of $\beta$-III-tubulin- positive cells is still much lower that that obtained when neurons are cocultured directly on the double KO SC astrocytes (Fig. 3, compare $A 1, B)$. This suggests that double KO SC astrocytes release trophic factors and/or diff usible molecules for neurons that can improve neuronal survival on an neutral substrate (i.e., the microporous membranes), but they are less efficient than the direct cell-cell contact achieved in the case of direct coculture.

To delineate the possible influence of those cell-cell contacts on neuronal survival, we tested a third experimental paradigm. Neocortical $+/+$ neurons were cultured on $+/+\mathrm{SC}$ astrocyte monolayers for $7 \mathrm{DIV}$ with the addition of $\mathrm{CM}$ from double $\mathrm{KO}$ or $+/+\mathrm{SC}$ astrocyte monolayers (Fig. $3 C$ ).

We observed that the number of $\beta$-III-tubulin-positive cells growing on $+/+$ astrocyte monolayers in the presence of the $\mathrm{CM}$, derived from $+/+$ or double KO SC astrocytes, was slightly increased when compared with neurons growing in standard conditions on $+/+$ astrocyte monolayers, with a mean increase of $171.15 \pm 16.08$ and $164.04 \pm 9.57 \%$ in $\beta$-III-tubulin-positive cells, respectively $(p<0.001)$. The difference with $+/+$ cultures $(100 \%$ 

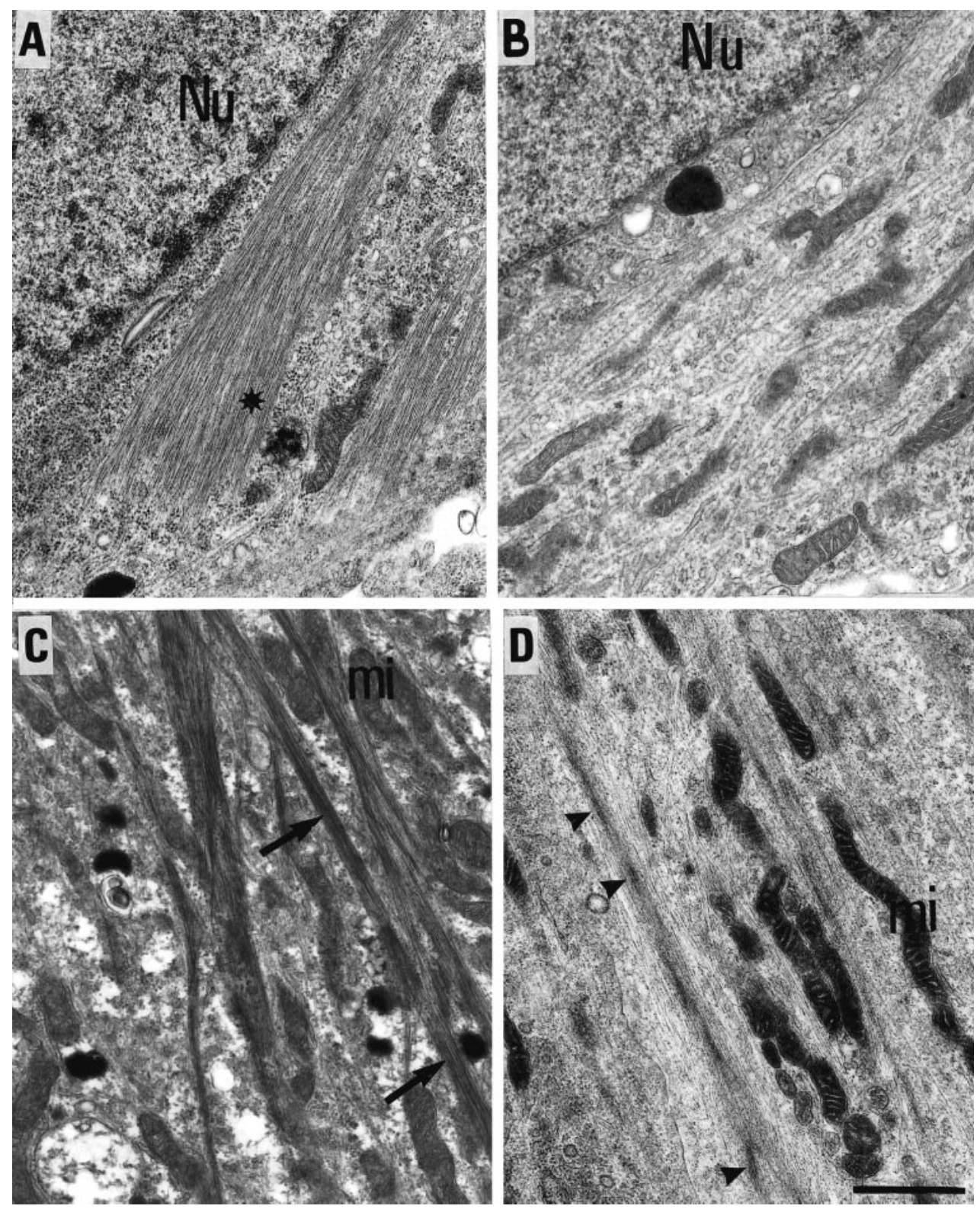

Figure 2. Electron micrographs of $+/+$ and mutant astrocytes after 15 DIV. $A$, Typical bundles of IFs are observed in $+/+$ astrocytes (asterisk). B, IFs are not detected in double $\mathrm{KO}$ astrocytes. $C, D$, Vim $-/$ - as well as GFAP $-/-$ astrocytes exhibit bundles of IFs, which are more closely packed than are those of $+/+$ astrocytes. However, the fine structure of glial filaments is slightly different between Vim-/ - and GFAP-/ - astrocytes. Whereas in the former individual filaments are well defined as in $+/+$ astrocytes and can be followed on long distances $(C$, arrows), in the latter, they appear poorly defined $(D$, arrowheads). $\mathrm{mi}$, Mitochondrion; $\mathrm{Nu}$, nucleus. Scale bar, $1 \mu \mathrm{m}$.

vs $171.15 \pm 16.08 \%$ ) could be explained by the fact that in the third paradigm, neurons are challenged with putative trophic factors since the beginning of the coculture, whereas in the first paradigm, such trophic factors are progressively built up and released by astrocytes.

However, we did not observe any significant differences between the two conditioned media (increase of $171.15 \pm 16.08$ and $164.04 \pm 9.57 \%$ in $\beta$-III-tubulin-positive cells). This absence of difference could be caused by some negative influence of direct contact with $+/+$ astrocytes. In addition, the number of neurons growing on $+/+\mathrm{SC}$ astrocytes in the presence of $+/+$ or double $\mathrm{KO} \mathrm{CM}$ was still much lower than that observed for neurons growing directly on double KO SC astrocyte monolayers by use of the first paradigm $(171.15 \pm 16.08$ and $164.04 \pm 9.57 \%$ vs $352.76 \pm 34.73 \% ; p<0.001)$. Thus, the results of the third paradigm suggest that soluble factors may, to a limited extent, improve neuronal survival but that only direct contact between neocortical neurons and double KO SC astrocytes increases significantly neuronal survival.

\section{Neurite growth is increased on double KO astrocytes}

We next examined the influence of astrocyte monolayers on neurite growth by measuring the percentage of surface occupied per neuron in cocultures (Fig. 4). In the first paradigm, +/+ cortical neurons seeded onto $+/+$ and double KO SC astrocyte monolayers were immunostained for $\beta$-III-tubulin after 7 DIV. The percentage of surface occupied per neuron was observed to be significantly higher when neurons were growing on double $\mathrm{KO}$ astrocytes with a mean of $0.48 \pm 0.03 \%$ vs $0.23 \pm 0.01 \%$ (Fig. $4 A 1, p<0.001$ ) for neurons growing on $+/+$ astrocyte monolayers. Moreover, $\beta$-III-tubulin-positive cells growing on double $\mathrm{KO}$ $\mathrm{SC}$ astrocyte monolayers were often organized in clusters and showed a more complex neuritic network (see Fig. 6, compare $A$, $B)$. Thus, the increased percentage of surface occupied by neurons observed on double $\mathrm{KO} \mathrm{SC}$ astrocytes was often, if not always, underestimated.

To eliminate the possible effects of contaminating cells (which could be present in SC astrocyte cultures) on neurite growth, we 
Figure 3. Cortical neuronal survival on cultured astrocytes. Quantification of $\beta$-III-tubulin-positive cells on 2-week-old primary cultured $+/+$ and double KO astrocytes. $A$, First paradigm. $A 1$, Neurons were cultured directly on $+/+$ or double KO SC astrocytes. A significantly higher survival can be observed when neurons were cultured on double KO SC astrocyte monolayers $\left({ }^{* * *} p<0.001\right.$, Mann-Whitney $U$ test). $A 2$, Neurons were cultured directly on $+/+$ or double KO cortical astrocytes. Note the significantly higher survival when neurons were cultured on double $\mathrm{KO}$ cortical astrocyte monolayers $\left({ }^{* * *} p<0.001\right.$, Mann-Whitney $U$ test) $B$, Second paradigm. Neurons were cocultured on microporous membranes in the presence of $+/+$ or double KO SC astrocyte monolayers. The number of $\beta$-III-tubulin-positive cells per square millimeter is significantly higher when neurons were cultured in the presence of double KO SC astrocytes versus $+/+\mathrm{SC}$ astrocytes $(* * * p<0.001)$. $C$, Third paradigm. Neurons were cocultured directly on $+/+$ astrocytes in the presence of $+/+$ or double KO SC conditioned media. The survival of $\beta$-IIItubulin neurons is significantly higher in the presence of the conditioned media $(* * * p<0.001)$. However, there are no significant differences between $+/+$ and double KO conditioned media.

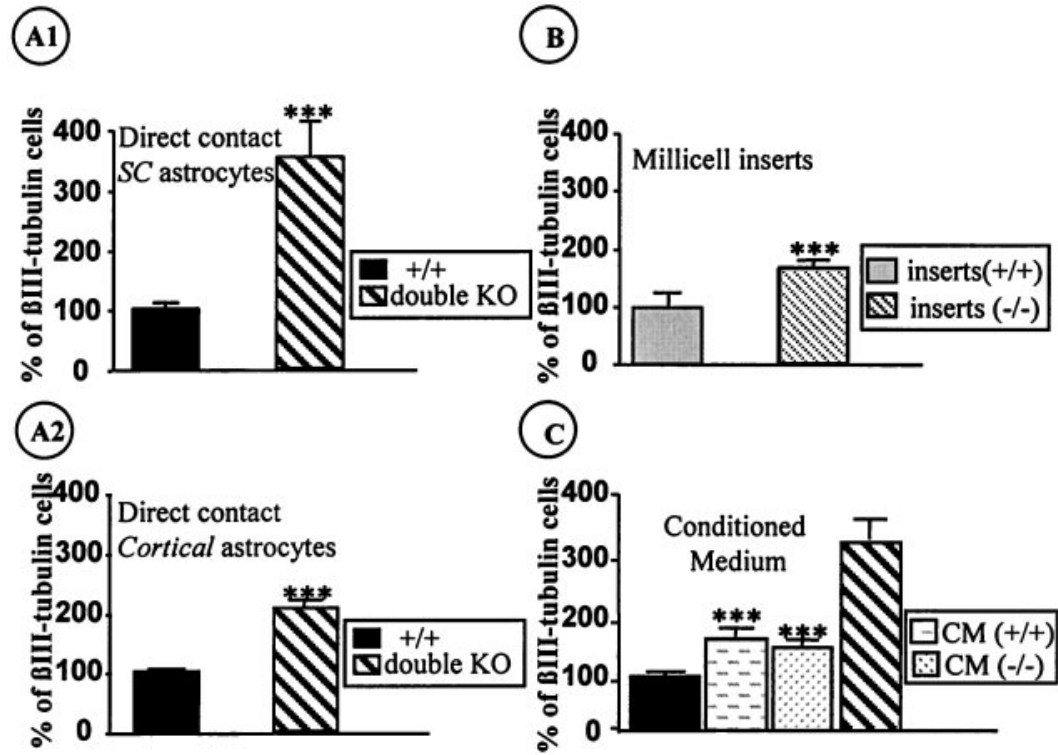

measured the percentage of surface occupied by neuron grown on cortical astrocytes. We observed that the surface occupied by neurons growing on double $\mathrm{KO}$ cortical astrocyte monolayers was again higher $(3 \times)$ than that of neurons growing on $+/+$ cortical astrocyte monolayers, with a mean of $0.46 \pm 0.06 \%$ vs $0.14 \pm$ $0.01 \%$ (Fig. $4 A 2, p<0.001$ ).

These results indicate that the increased neurite growth observed on double KO primary glial cultures is dependent on astrocytes per se. Moreover, the comparison of homotopic and heterotopic cocultures showed us that increased neurite growth is not dependent on the regional origin of the astrocytes.

The ability of secreted factors to promote neurite growth was tested with our third paradigm, in which neurons were grown on $+/+\mathrm{SC}$ astrocyte monolayers in the presence of the $+/+$ or double KO SC conditioned medium (Fig. 4B). We observed that there were no differences between neurons growing on $+/+$ astrocyte monolayers in the presence of $+/+$ or double $\mathrm{KO} \mathrm{SC}$ conditioned medium and neurons growing on $+/+$ astrocyte monolayers, with a mean of $0.40 \pm 0.05$ and $0.38 \pm 0.04 \%$ versus $0.35 \pm 0.05 \%$, respectively, whereas for neurons growing directly on double KO SC astrocytes, the occupied surface was significantly higher $(0.57 \pm 0.06 \% ; p<0.001)$.

Thus, double KO SC astrocytes are a more favorable substrate than are $+/+$ SC astrocytes for both neuronal survival and neurite growth, and the latter seems to be strictly contact dependent, whereas survival could also depend partially on neurotrophic and/or diffusible factors.

We next wanted to determine whether vimentin plays a role in this phenomenon. For that purpose, we compared Vim-1- or GFAP $-/-$ astrocytes with the $+/+$ astrocytes in their interactions with cocultured neurons in the first paradigm.

\section{Characterization of the Vim-/- and GFAP-/- astroglial cultures}

As expected, Vim-/- or GFAP-/- primary cultured SC astrocytes were negative for Vim and GFAP immunostaining, respectively (Fig. $1 H, J)$.

In Vim-/- astrocyte monolayers, GFAP immunostaining (Fig. $1 G$ ) was generally similar to that observed in $+/+$ astrocytes (Fig. $1 A$ ) despite the fact that GFAP-immunoreactive profiles were more tightly packed (Fig. $1 G$, asterisk). Nestin immunostaining was predominantly diffuse throughout the cytoplasm of the cells
(Fig. 1I), as seen in double $\mathrm{KO}$ astrocytes with an exception in a few cells in which the nestin antibody decorated a network composed of short bundles of filaments (Fig. 1I, arrowhead).

In GFAP-/- astrocytes, the Vim immunostaining (Fig. $1 K$ ) was qualitatively similar to that observed in $+/+$ astrocytes (Fig. $1 B)$. We also observed that the majority of perikarya and processes were nestin-positive (Fig. $1 L$ ) with a pattern similar to that observed in $+/+$ astrocytes (Fig. 1C).

As expected, Western blot analysis from cultured single mutant astrocytes confirmed the total absence of Vim or GFAP in Vim-/- or GFAP-/- astrocyte monolayers, respectively (data not shown).

At the electron microscopy level, in Vim-/- astrocytes, bundles of filaments (Fig. 2C) appeared narrow, very dense, and more packed than those in $+/+$ astrocytes. In GFAP $-/-$ astrocytes, IFs were also more packed (Fig. 2D) than those in $+/+$ astrocytes. However, they appeared slightly less well defined as separate, continuous entities than those in $+/+$ and in Vim $-/-$ astrocytes.

\section{The sole absence of GFAP increased both neuronal survival and neurite growth}

We have shown recently that GFAP-/- astrocytes were a favorable substrate for neuronal survival and neurite growth in vitro. To evaluate specifically the influence of Vim on neuronal survival and neurite growth, we compared the permissivity of Vim-/- or GFAP $-/-$ astrocytes using the standard coculture paradigm.

We first observed that the neuronal density (Figs. 5A, 6) was not significantly different when neurons were grown on Vim-/$\mathrm{SC}$ astrocyte monolayers versus $+/+\mathrm{SC}$ astrocyte monolayers $(83.64 \pm 8.9 \%$ vs $100 \%)$. Moreover, we confirmed that GFAP-/$\mathrm{SC}$ astrocytes were a more favorable substrate for neuronal survival compared with $+/+\mathrm{SC}$ astrocytes $(360.87 \pm 50.3 \%$; $p<$ 0.001 ), in a way similar to double KO SC astrocytes (see above, $357.16 \pm 56.9 \%$ of $\beta$-III-tubulin-positive cells).

We then compared the Vim-/- and GFAP-/- SC astrocytes in their ability to support neurite growth (Figs. $5 B, 6$ ). Neurite extension was quantified in terms of neurite lengths (micrometers) per neuron: we chose neurons that were isolated and not packed into clusters. Neurons growing on Vim-/- SC astrocytes extend neurites in a way similar to that of neurons growing on $+/+$ SC astrocytes $(531.4 \pm 45.8 \mu \mathrm{m}$ vs $495.28 \pm 44.5 \mu \mathrm{m})$. When neurons were growing on GFAP-/- SC astrocytes, they had 


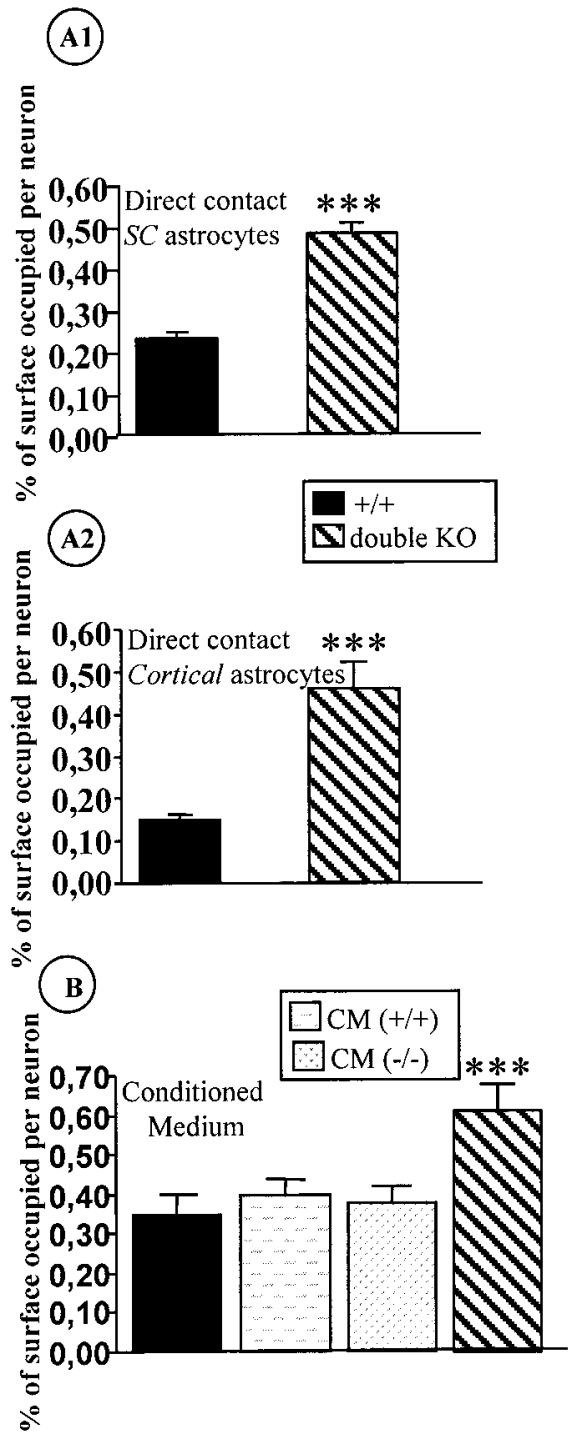

Figure 4. Cortical neurite growth on cultured astrocytes. Quantification of the percentage of surface occupied per $\beta$-III-tubulin-positive cells. $A$, First paradigm. $A 1$, Neurite growth of neurons cocultured directly on $+/+$ or double KO SC astrocytes. Neurite growth is significantly higher when neurons were growing on double KO SC astrocytes $(* * * p<0.001) . A 2$, Neurite growth of neurons cocultured directly on $+/+$ or double KO cortical astrocytes. Note the significantly higher growth when neurons were growing on double $\mathrm{KO}$ cortical astrocytes $(* * p<0.001)$. $B$, Third paradigm. Neurite growth of neurons directly cocultured on $+/+$ astrocytes in the presence of $+/+$ or double KO SC conditioned media. There are no significant differences between neurons growing directly on $+/+$ astrocytes or neurons growing on $+/+$ astrocytes in the presence of the conditioned media.

more neurites and extended them much farther than on $+/+\mathrm{SC}$ astrocytes $(1125.9 \pm 82.2 \mu \mathrm{m}$ vs $495.28 \pm 44.5 \mu \mathrm{m} ; p<0.001)$. Again, this extension of neurites for neurons growing on GFAP-/- SC astrocytes was similar to that measured for neurons growing on double KO SC astrocytes $(1125.9 \pm 82.2 \mu \mathrm{m}$ vs $1061.3 \pm 78.6 \mu \mathrm{m})$.

\section{The absence of GFAP is correlated to a modified expression of ECM and adhesion molecules}

It is well known that cell-cell contact is primarily involved in axonal growth, notably by ECM and adhesion molecules. Having demonstrated that both double KO and GFAP-/- SC astrocytes increased neurite growth versus control, we first sought to exam-

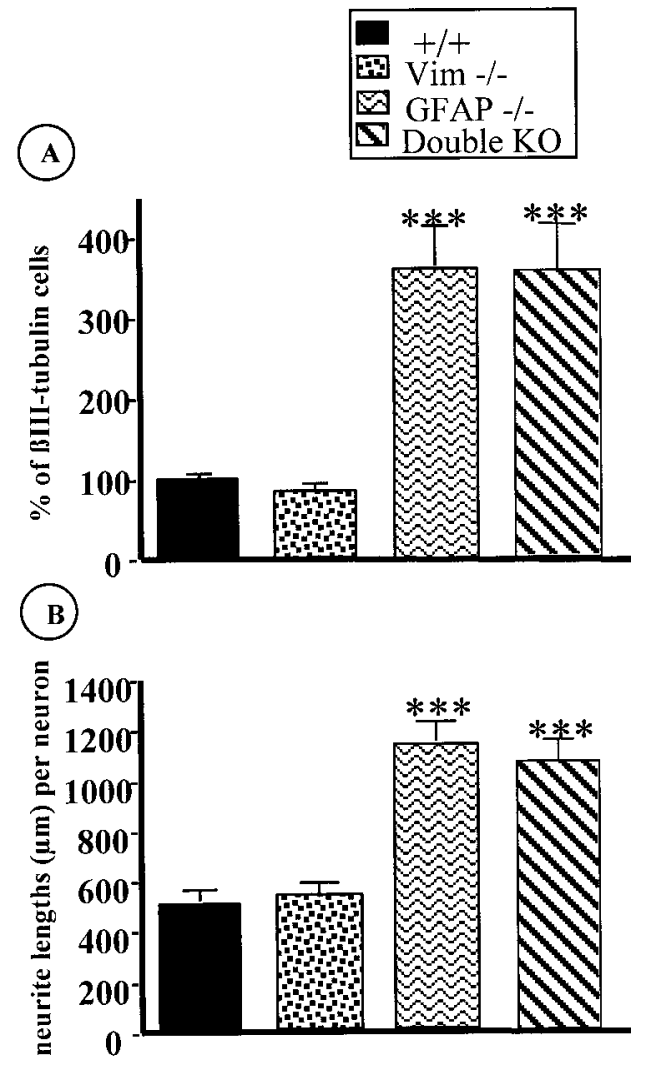

Figure 5. Cortical neuronal survival and neurite growth on GFAP-/-, Vim $-/-$, and double KO astrocytes. $A$, Quantification of $\beta$-III-tubulinpositive cells per square millimeter cocultured on $+/+$, Vim $-/-$, GFAP $-/-$, or double KO astrocyte monolayers. Note the significantly higher survival when neurons are growing on both GFAP-/- and double KO astrocytes (***p $<0.001$, Mann-Whitney). $B$, Quantification of neurite length $(\mu \mathrm{m})$ per isolated $\beta$-III-tubulin-positive cell. Here, note again the significantly higher neurite growth for neurons growing on GFAP $-/-$ and double KO astrocytes, whereas a similar neurite growth was evaluated between neurons growing on $+/+$ or Vim $-/-$ astrocytes $(* * * p<0.001)$.

ine the expression of laminin and chondroitin sulfate proteoglycans, of which the coexistence and antagonistic properties have been well demonstrated (McKeon et al., 1995; Zuo et al., 1998). Indeed, laminin is a major component of the ECM (Bixby et al., 1988; Sanes, 1989) known to be one of the strongest ECM component promoters for neurite growth (Baron-Van Evercooren et al., 1982; Sanes, 1989; Reichardt and Tomaselli, 1991), whereas chondroitin sulfate proteoglycans inhibit neurite outgrowth (McKeon et al., 1991; Letourneau et al., 1992)

In $+/+$ as well as in Vim $-/-\mathrm{SC}$ astrocyte monolayers, laminin was restricted to certain groups of cells (Fig. 7A,C, arrows). Conversely, in both double $\mathrm{KO}$ SC astrocytes and GFAP-/- SC astrocyte monolayers, the laminin staining was uniform, more intense, and widespread throughout the culture (Fig. 7B,D, arrowheads). For chondroitin sulfate proteoglycans (detected by the anti-CS56 monoclonal antibody that recognizes both CS4-PG and CS6-PG), we did not observe any obvious differences in the pattern of expression between all of the astrocytes studied (Fig. 7), although it was somewhat less intense in the GFAP-/- SC astrocyte cultures, as it has been described previously in vivo in the SC of GFAP-/- mice (Wang et al., 1997). No colocalization was observed for laminin and CS56. Western blot analysis of laminin (see Fig. 9B) confirmed that its expression was significantly increased in GFAP-/ - SC astrocytes $(1.9 \pm 0.01 \times ; p<$ $0.01)$ and double KO SC astrocytes $(1.39 \pm 0.01 \times ; p<0.01)$ 


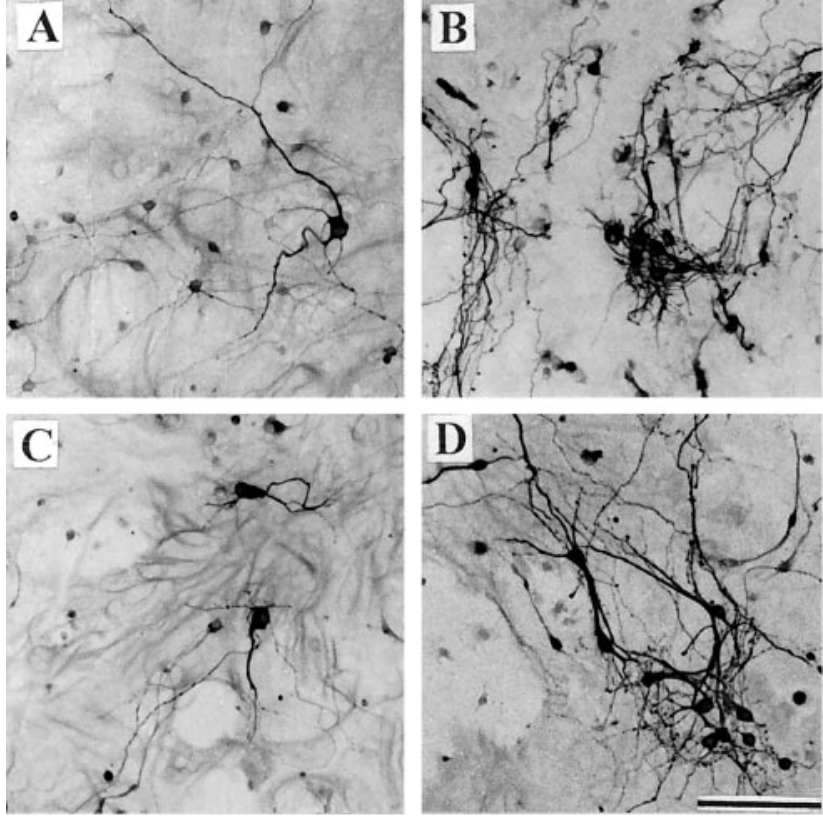

Figure 6. Immunocytochemical characterization of cocultured neurons on astrocyte monolayers by $\beta$-III-tubulin detection. A high density of $\beta$-III-tubulin neurons with a complex network can be observed on both double $\mathrm{KO}(B)$ and GFAP-/- $(D)$ astrocytes, whereas a low density of neurons with few neurite extensions is observed on $+/+(A)$ and Vim-/(C) astrocytes. Scale bar, $100 \mu \mathrm{m}$.

compared with the expression in $+/+$ or $\mathrm{Vim}-/-(1.02 \pm 0.01 \times$; NS) SC astrocytes.

We next decided to look for the following key molecules known to be implicated in the permissivity of astrocytes: fibronectin, N-cadherin, and N-CAM. These three molecules, which are expressed on astrocytes in vitro (Noble et al., 1985; Price and Hynes, 1985; Liesi et al., 1986; Tomaselli et al., 1988), are known to be involved in neurite growth during development (Keilhauer et al., 1985; Noble et al., 1985; Neugebauer et al., 1988; Tomaselli et al., 1988; Matthiessen et al., 1989). They are then downregulated during the maturation of astrocytes (Smith et al., 1990, 1993).

The immunostaining for fibronectin exhibited very different patterns of expression between all of the astrocyte cultures. Indeed, in $+/+$ astrocyte monolayers, we observed a moderate intracellular staining throughout the cultures and a very limited extracellular staining that was constituted of very thick, fibrous strands (Fig. $8 A$, arrow). In all of the mutant astrocyte cultures, the intensity of the immunostaining was enhanced versus control. In Vim-/- astrocyte cultures, the fibronectin staining was mostly extracellular with a network of very thin, packed fibrillar deposits in many areas of the culture (Fig. $8 C$ ). Conversely, GFAP-/and double $\mathrm{KO}$ astrocytes exhibited the same distribution of fibronectin. Although immunostaining for fibronectin was mainly intracellular, some thick fibrillar deposits of fibronectin are already found as it was described in $+/+$ astrocyte cultures (Fig. $8 B, D$, arrows). Interestingly, most of the extracellular expression of fibronectin appears as in a punctuate labeling (Fig. 8B,D, arrowheads). This latter pattern of expression of fibronectin was never observed in $+/+$ or in Vim $-/-$ astrocyte cultures.

By Western blot, we observed a slight but significant increase in the expression of fibronectin in the three mutant extracts $(\mathrm{Vim}-/-, 2.45 \pm 0.03 \times ; p<0.05 ;$ GFAP $-/-, 1.92 \pm 0.02 \times ; p<$ 0.05 ; and double $\mathrm{KO}, 1.83 \pm 0.02 \times ; p<0.05)$ versus the $+/+$ extract (Fig. 9A). Although the increase is most evident in
Vim-/- astrocytes, the difference did not reach statistical significance between the three mutant extracts.

The expression of $\mathrm{N}$-cadherin (Fig. 9C) was significantly enhanced in GFAP $-/-\mathrm{SC}$ astrocytes $(4.23 \pm 0.09 \times ; p<0.005)$ as well as in double KO SC astrocytes $(1.5 \pm 0.01 \times ; p<0.05)$, whereas there was no difference between $+/+$ and $\mathrm{Vim}-/-$ $(1.17 \pm 0.02 \times)$ SC astrocytes.

Finally, we did not observe any obvious difference in the $\mathrm{N}-\mathrm{CAM}$ expression between all of the astrocyte monolayers studied (Fig. 9D). Indeed, the $140 \mathrm{kDa}$ subunit, which is the major subunit of N-CAM present on astrocyte membranes (Noble et al., 1985), is expressed in a similar way in $+/+$ or mutant astrocytes $($ Vim-/-, $0.96 \pm 0.06 \times$; GFAP-/-, $0.94 \pm 0.05 \times$; double KO, $0.9 \pm 0.03 \times$; NS). Moreover, we only detected a slight expression of the two other subunits of N-CAM (the 120 and $180 \mathrm{kDa}$ subunits), which are minor subunits on astrocyte membranes.

\section{DISCUSSION}

In the present study, we first demonstrated that double $\mathrm{KO}$ astrocytes are a favorable substratum both for neuronal survival and neuritogenesis. These effects were not region-specific dependent because cortical and SC double $\mathrm{KO}$ astrocytes have a similar influence on $+/+$ neocortical neurons. Second, for these two parameters, the absence of Vim is not a key element in the permissivity of KO astrocytes. Finally, we have shown that the sole absence of GFAP is correlated with significant modifications in the expression of ECM and of adhesion molecules.

\section{Choice of model}

Astrocyte hypertrophy is one major element in the formation of the glial scar (Fawcett and Asher, 1999) and is characterized by a massive increase of the IFs proteins GFAP and Vim (Bignami and Dahl, 1976, Bignami et al., 1982; Schiffer et al., 1986).

Here we analyzed, in a simplified in vitro system, the consequences of the absence of GFAP and/or Vim on neuronal survival and neuritogenesis, two key parameters for axonal regeneration after injury. For that purpose, we took advantage of the GFAP-/(Pekny et al., 1995) and the Vim-/- (Colucci-Guyon et al., 1994) mice generated previously, and we crossed them to obtain double KO mice (Giménez y Ribotta et al., 2000). In our coculture model, neurons were challenged with their SC target region-derived astrocytes. In this condition, astrocytes represent at least $85 \%$ of the glial cultures. To eliminate the eventual effects of contaminating cells on the two parameters tested, we analyzed also cortical primary glial cultures that contain $>95 \%$ astrocytes. This permitted us also to test the influence of homotopic versus heterotopic astrocytes because neuron-astrocyte interactions are strongly influenced by their relative anatomical location within the CNS (Chamak et al., 1987; Qian et al., 1992; Dijkstra et al., 1999).

\section{Is the absence of GFAP linked to the immaturity of astrocytes?}

In the absence of both GFAP and Vim, astrocytes still expressed the IF protein nestin, which appeared to be diffusely spread in the perikaryon, whereas condensed fibrous bundles were observed in $+/+$ astrocytes and in GFAP $-/-$ astrocytes. These findings confirmed the observations of Eliasson et al. (1999) in another CNS region. However, at variance with the latter, the observation of polymerized nestin in a few Vim-/ - astrocytes could suggest that GFAP may promote the nestin assembly into short filaments but is unable to organize a nestin network. This confirms that nestin does not organize itself into a cytoplasmic network and that, in primary cultured astrocytes, it needs vimentin but not GFAP to do it (Marvin et al., 1998). 

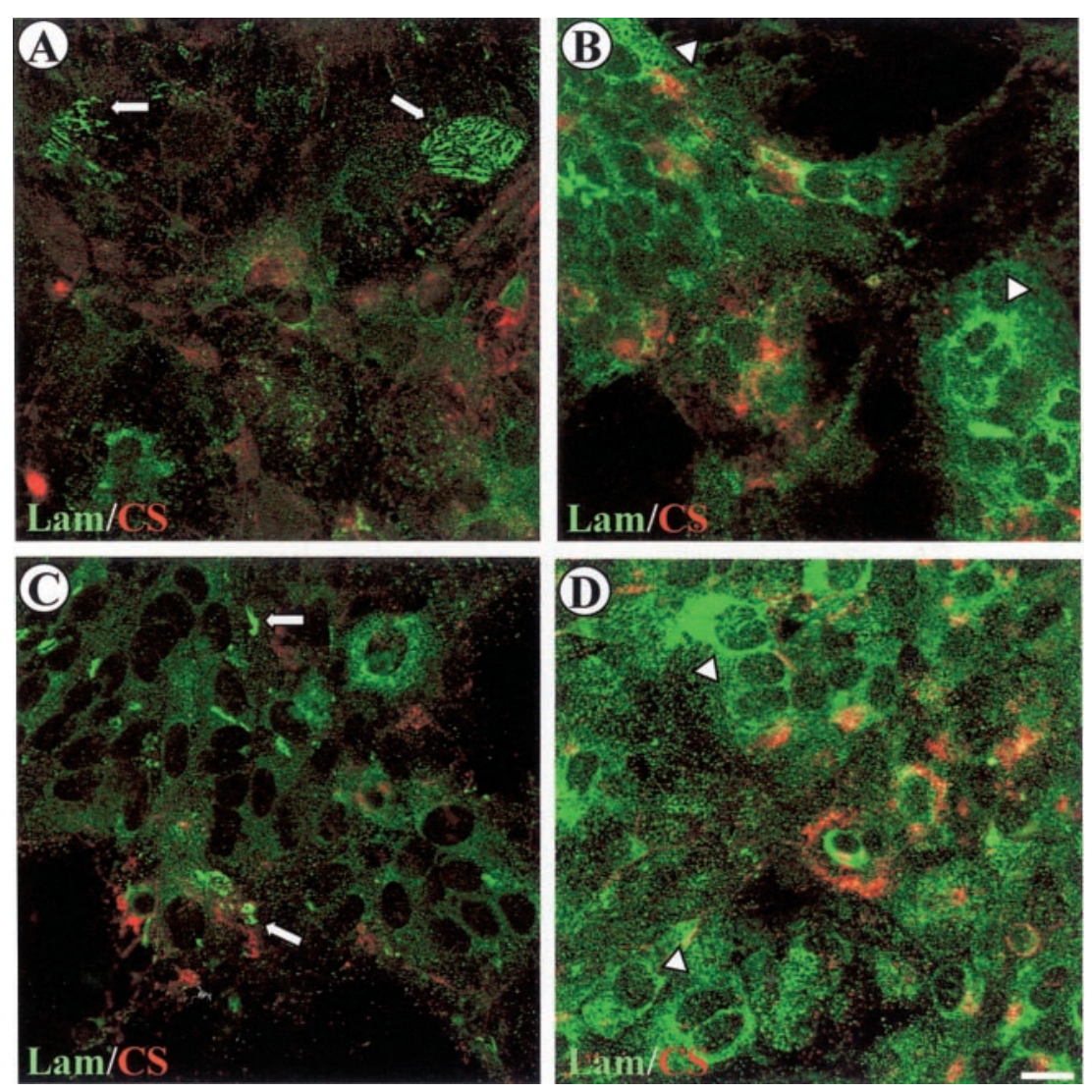

Figure 7. Double immunofluorescence for laminin and chondroitin sulfate proteoglycan (CS56) detection on astrocyte monolayers after 15 DIV. Laminin immunostaining (green) is restricted to a certain group of cells in $+/+$ ( $A$, arrows $)$ and Vim $-1-(C$, arrows $)$ astrocytes, whereas it seems homogenous and widespread throughout the cytoplasm and not restricted to cell patches in double $\mathrm{KO}$ $(B$, arrowheads $)$ and GFAP $-/-(D$, arrowheads $)$ astrocytes. Conversely, no differences between all of the astrocyte monolayers $(A-D)$ are observed concerning the staining intensity and the distribution of CS56 (red). Lam, Laminin. Scale bar, $15 \mu \mathrm{m}$.
At variance with $+/+$ astrocytes, double $\mathrm{KO}$ and, to a lesser extent, GFAP-/- astrocytes exhibit an epithelioid shape (data not shown), with small processes, suggesting a variable degree of immaturity. Indeed, the formation of radiating processes together with a decrease in the concentration of microtubules has been described during the maturation of astrocytes (Vaughn and Peters, 1967; Privat, 1975). Moreover in vivo studies of double KO mice in our laboratory (Giménez y Ribotta et al., 2000) have demonstrated evidence of immaturity for cerebellar Bergmann glia, which normally coexpress GFAP and Vim (Shaw et al., 1981).

Here, we observed other features of immaturity in both double $\mathrm{KO}$ and GFAP $-/-$ astrocytes, such as an increased expression of laminin and $\mathrm{N}$-cadherin. Both are present during CNS development, in immature astrocytes, and decrease during maturation (Liesi et al., 1983; Smith et al., 1990, 1993). Altogether, these results indicate that double $\mathrm{KO}$ and GFAP-/- astrocyte monolayers display morphological and biochemical characteristics of immature astrocytes, which are known to be more permissive for neurite outgrowth than are adult ones (Bovolenta et al., 1984; Smith et al., 1990; Hatten et al., 1991).

\section{Is the absence of GFAP linked to a higher neuronal survival and neurite growth?}

We observed that both double KO and GFAP-/- astrocytes are a more favorable substrate for neuronal survival and neurite growth than are $+/+$ astrocytes. Conversely, the sole absence of Vim does not appear to have a key influence in the two parameters evaluated. These data confirm a correlation between the differential expression of IFs proteins and the decrease of permissivity (Bovolenta et al., 1984; Hatten et al., 1991).

In agreement with this, we have shown previously that tanycytes, a particular type of astrocytes expressing little if any GFAP (Chauvet et al., 1995), support better neuronal survival and neurite growth in vitro than regular astrocytes do (Chauvet et al., 1996). To assess the potential role of diffusible factors on neuronal survival, we performed noncontact cocultures. Although our results suggest that double $\mathrm{KO}$ astrocytes could release, to a limited extent, trophic factors (Henderson, 1996) and/or diffusible molecules, as tanycytes do (Chauvet et al., 1996), we found that cell-cell contacts between double KO astrocytes and neurons were the key element. This could suggest that (1) trophic factors are fragile and quickly degraded, thus requiring a permanent supply to be efficient, as is the case with the use of microporous inserts, and (2) neuronal-promoting survival by double $\mathrm{KO}$ astrocytes is mediated via the expression of specific-bound molecules in addition to diffusible factors.

Most interestingly, double KO astrocytes as well as GFAP-/astrocytes enhanced neurite growth. In addition, we demonstrated that both double KO SC and cortical astrocytes enhanced significantly neuritic outgrowth of embryonic neocortical neurons, thus excluding the possible role of contaminating cell populations and showing that it is not region-specific dependent. In our experiment, we have not discriminated between axonal and dendritic growth. Thus, our results are not at variance with those of Chamak et al. (1987) and Qian et al. (1992) who reported that axonal growth was more stimulated in heterotopic cocultures, whereas Le Roux and Reh (1994) reported that dendritic growth was increased in homotopic cocultures. Finally, we observed that a $\mathrm{CM}$ from $+/+$ or double $\mathrm{KO}$ astrocyte cultures did not increase neurite growth. This establishes cell-cell contact as mandatory for neurite growth on $\mathrm{KO}$ astrocytes, as found previously with tanycytes (Chauvet et al., 1996).

\section{Is the absence of GFAP associated with modifications} in the ECM and membrane molecules?

We have found that GFAP-/- and double KO astrocytes exhibited a different organization of the ECM. First, laminin is over- 

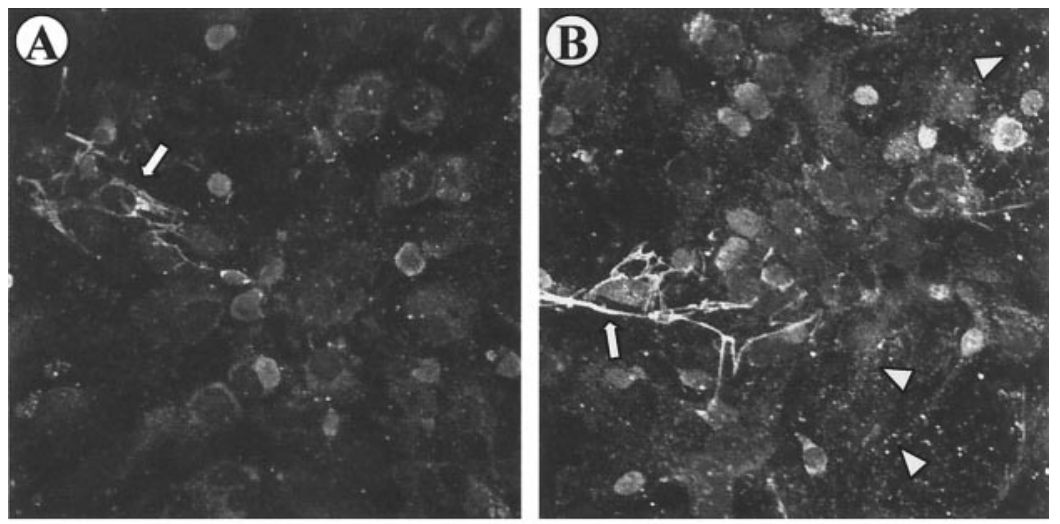

Figure 8. Immunofluorescence for fibronectin on astrocyte monolayers after 15 DIV. $A,+/+$ astrocytes exhibit a slight expression of fibronectin with a very limited extracellular staining (arrow). $B, D$, Double KO astrocytes $(B)$ as well as GFAP-/- astrocytes $(D)$ exhibit an intracellular staining with some thick extracellular fibrillar deposits of fibronectin $(B, D$, arrows). Interestingly, note the punctuate extracellular labeling of fibronectin $(B, D$, arrowheads) that is never observed in $+/+$ or Vim-l- astrocytes. $C$, Vim-/- astrocytes exhibit an intense extracellular staining composed of a thin fibrillar network of fibronectin all over the culture. Scale bar, $20 \mu \mathrm{m}$.
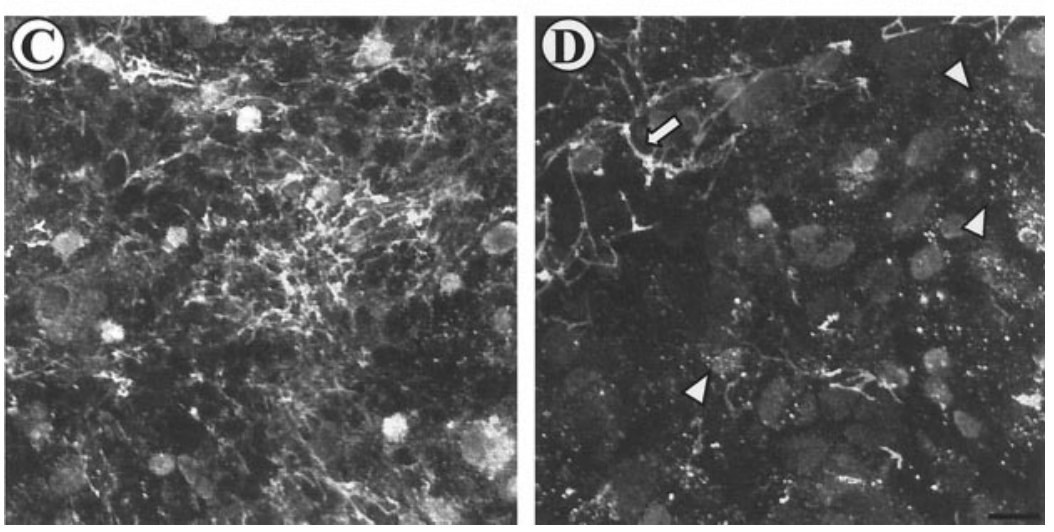

expressed on both GFAP-/- and double KO astrocytes with a homogenous distribution compared with the patchy appearance found in $+/+$ and Vim $-/-$ astrocytes. Second, the punctuate aggregates of fibronectin observed only on GFAP-/- and double $\mathrm{KO}$ astrocytes are similar to those observed in close association with radial glia during development (Sheppard et al., 1991) and also in the migratory pathway of neural crest cells (Brauer and Markwald, 1988). Surprisingly, Vim-/- astrocytes exhibit the highest level and the most developed extracellular network of fibronectin. This could appear at odds with the fact that Vim-/astrocytes are a poor substrate for neurite growth, because fibronectin is known to promote axon growth (Liesi et al., 1986; Matthiesen et al., 1989). However, fibronectin is also increased in inhibitory glial scars (McKeon et al., 1991) and particularly on meningeal cells, forming an extensive extracellular matrix (Hirsch and Bähr, 1999). Thus, our results may suggest (1) that the high content of fibronectin (as found in Vim-/- astrocytes) is not per se permissive in the absence of other potential growth molecules or (2) that punctuate aggregates of fibronectin (as found in double $\mathrm{KO}$ and GFAP $-/-$ astrocytes) are more effective in forming complexes with other permissive ECM molecules. Reorganizations in the GFAP network have indeed been correlated with modifications of the ECM (Baghdassarian et al., 1993; Trentin and Moura-Neto, 1995).

Interestingly, N-cadherin, which plays key roles during CNS development (Redies, 2000), is overexpressed on GFAP-/- and double $\mathrm{KO}$ astrocytes. At variance, N-CAM expression is not significantly modified in all cultured astrocytes. N-CAM requires a cytoplasmic domain to have neuritogenetic properties (Safell et al., 1995), but the $140 \mathrm{kDa}$ subunit of N-CAM does not interact with the cytoskeleton (Pollerberg et al., 1987). Because no differences were observed in N-CAM expression, we can hypothesize that (1) N-CAM is not a key element in the permissivity of double $\mathrm{KO}$ and GFAP $-/-$ astrocytes and (2) the absence of GFAP is only correlated with modifications of some ECM and adhesion molecules that are linked to the cytoskeleton.

\section{What is the link between the absence of GFAP and the modifications of the expression of ECM and of adhesion molecules?}

The actin cytoskeleton is directly coupled to N-cadherin (Aberle et al., 1995), but also to laminin and fibronectin directly via the $\beta 1$ integrin subunit (Schoenwaelder and Burridge, 1999). It is also well established that cross-bridges exist between the various components of the cytoskeleton (Fuchs and Yang, 1999; Goldman et al., 1999; Klymkowsky, 1999), in particular through the IFassociated proteins (Coulombe et al., 2000; Herrmann and Aebi, 2000). Thus, IFs and microtubules (Goldman, 1971; Yang et al., 1992) as well as IFs and microfilaments (Hubbard and Lazarides, 1979) are closely linked. Specifically, Vim is in close relation with actin (Cary et al., 1994), and the actin network is altered in Vim-/- fibroblasts (Eckes et al., 1998).

So, we cannot exclude that a dynamic equilibrium exists between GFAP, Vim, and actin. The absence of GFAP could induce an organization of the actin network leading to an increased expression of ECM and adhesion molecules, thus yielding an enhanced permissivity of astrocytes. Finally, we cannot exclude in addition that the absence of GFAP induces modifications in transmission of the mechanical and/or biochemical signals because IFs constitute a link between the nucleus and the cell surface (Goldman et al., 1986).

To conclude, we have shown here that one molecule, GFAP, rather than the presence of glial filaments per se can influence the permissivity of astrocytes for neuronal survival and neurite growth. Interestingly, this corresponds to the developmental sequence of expression of Vim and GFAP, the former being present in immature permissive astrocytes and the latter in adult, nonpermissive, ones. This is clearly correlated with a specific pattern 

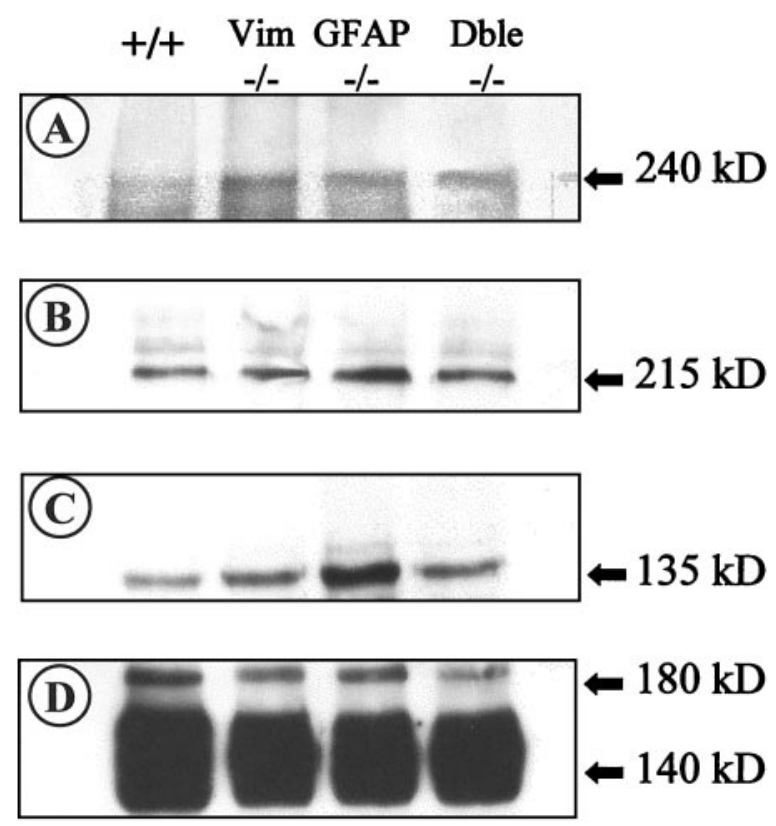

Figure 9. Western blot analysis of ECM and of adhesion molecules in astrocyte cultures after 15 DIV. $A$, Fibronectin expression is increased in all three mutant astrocytes versus $+/+$ astrocytes, although the highest expression of fibronectin is in the Vim-/- extract. $B, C$, Laminin expression $(B)$ and $\mathrm{N}$-cadherin expression $(C)$ are increased in GFAP-/- and double $-/-$ extracts versus Vim $-/-$ and $+/+$ extracts. The most important increase is always observed in the GFAP-/- extract. $D$, No differences in the expression of the $140 \mathrm{kDa}$ subunit of N-CAM can be observed between all of the extracts. Note the slight expression of the 180 kDa subunit. Dble, Double.

of surface molecules. At the present time, we cannot decide whether the absence of GFAP per se can directly modify the other components of the astrocytic cytoskeleton inducing biochemical changes in ECM and membrane properties. However, our data suggest that GFAP expression and network formation are associated with key events in the astroglial differentiation. There may also exist genomic complex regulators operating during CNS maturation, in which the expression of GFAP could be a limiting factor. Whatever the case, the present study constitutes the necessary background for further manipulation of the astrocytic scar to stimulate axonal regeneration in vivo.

\section{REFERENCES}

Abd-el-Basset EM, Ahmed I, Kalnins VI, Fedoroff S (1992) Immunoelectron microscopical localization of vimentin and glial fibrillary acidic protein in mouse astrocytes and their precursor cells in culture. Glia 6:149-153.

Aberle H, Schwartz H, Kemler R (1995) Cadherin-catenin complex: protein interactions and their implications for cadherin function. J Cell Biochem 61:514-523.

Baghdassarian D, Toru-Delbauffe D, Gavaret JM, Pierre M (1993) Effects of transforming growth factor- $\beta 1$ on the extracellular matrix and cytoskeleton of cultured astrocytes. Glia 7:193-202.

Baron-Van Evercooren A, Kleinman HK, Ohno S, Marangos P, Schwartz JP, Dubois-Dalcq ME (1982) Nerve growth factor, laminin, and fibronectin promote neurite growth in human fetal sensory ganglia cultures. J Neurosci Res 8:179-193.

Bignami A, Dahl D (1976) The astrocytic response to stabbing. Immunofluorescence studies with antibodies to astrocytic-specific protein (GFAP) in mammalian and submammalian vertebrates. Neuropathol Appl Neurobiol 2:99-110.

Bignami A, Dahl D (1989) Vimentin-GFAP transition in primary dissociated cultures of rat embryo spinal cord. Int J Dev Neurosci 7:343-357.

Bignami A, Raju T, Dahl D (1982) Localization of vimentin, the nonspecific intermediate filament protein, in embryonal glia and in early differentiating neurons. In vivo and in vitro immunofluorescence study of the rat embryo with vimentin and neurofilament antisera. Dev Biol 91:286-295.
Bixby JL, Lilien J, Reichardt LF (1988) Identification of the major proteins that promote neuronal process outgrowth on Schwann cells in vitro. J Cell Biol 107:353-361.

Bovolenta P, Liem RK, Mason CA (1984) Development of cerebellar astroglia: transitions in form and cytoskeletal content. Dev Biol 102:248-259.

Brauer PR, Markwald RR (1988) Specific configurations of fibronectincontaining particles correlate with pathways taken by neural crest cells at two axial levels. Anat Rec 222:69-82.

Brown JO, McCough GP (1947) Abortive regeneration of the transected spinal cord. J Comp Neurol 87:131-137.

Cary RB, Klymkowsky MW, Evans RM, Domingo A, Dent JA, Backhus LE (1994) Vimentin's tail interacts with actin-containing structures in vivo. J Cell Sci 107:1609-1622.

Chamak B, Fellous A, Glowinski J, Prochiantz A (1987) MAP-2 expression and neuritic outgrowth and branching are coregulated through region-specific neuro-astroglial interactions. J Neurosci 7:3163-3170.

Chauvet N, Parmentier ML, Alonso G (1995) Transected axons of adult hypothalamo-neurohypophysial neurons regenerate along tanycytic processes. J Neurosci Res 41:129-144.

Chauvet N, Privat A, Alonso G (1996) Aged median eminence glial cell cultures promote survival and neurite outgrowth of cocultured neurons. Glia 18:211-223.

Chiu FC, Norton WT, Fields KL (1981) The cytoskeleton of primary astrocytes in culture contains actin, glial fibrillary acidic protein, and the fibroblast-type filament protein, vimentin. J Neurochem 37:147-155.

Ciesielski-Treska J, Goetschy JF, Aunis D (1988) Acquisition of vimentin in astrocytes cultured from postnatal rat brain. J Neurocytol 17:79-88.

Clarke SR, Shetty AK, Bradley JL, Turner DA (1994) Reactive astrocytes express the embryonic intermediate neurofilament nestin. NeuroReport 5:1885-1888.

Colucci-Guyon E, Portier MM, Dunia I, Paulin D, Pournin S, Babinet C (1994) Mice lacking vimentin develop and reproduce without an obvious phenotype. Cell 79:679-694.

Coulombe PA, Bousquet O, Ma L, Yamada S, Wirtz D (2000) The "ins" and "outs" of intermediate filament organization. Trends Cell Biol 10:420-428.

Dahl D, Rueger DC, Bignami A, Weber K, Osborn M (1981a) Vimentin, the 57,000 molecular weight protein of fibroblast filaments, is the major cytoskeletal component in immature glia. Eur J Cell Biol 24:191-196.

Dahl D, Bignami A, Weber K, Osborn M (1981b) Filament proteins in rat optic nerves undergoing Wallerian degeneration: localization of vimentin, the fibroblastic $100-\mathrm{A}$ filament protein, in normal and reactive astrocytes. Exp Neurol 73:496-506.

Dahlstrand J, Lardelli M, Lendahl U (1995) Nestin mRNA expression correlates with the central nervous system progenitor cell state in many, but not all, regions of developing central nervous system. Brain Res Dev Brain Res 84:109-129.

Dijkstra S, Bär PR, Gispen WH, Joosten EAJ (1999) Selective stimulation of dendrite outgrowth from identified corticospinal neurons by homotopic astrocytes. Neuroscience 92:1331-1342.

Eckes B, Dogic D, Colucci-Guyon E, Wang N, Maniotis A, Ingber D, Merckling A, Langa F, Aumailley M, Delouvee A, Koteliansky V, Babinet C, Krieg T (1998) Impaired mechanical stability, migration and contractile capacity in vimentin-deficient fibroblasts. J Cell Sci 111:1897-1907.

Eliasson C, Sahlgren C, Berthold CH, Stakeberg J, Celis JE, Betsholtz C, Eriksson JE, Pekny M (1999) Intermediate filament protein partnership in astrocytes. J Biol Chem 274:23996-24006.

Fawcett JW, Asher RA (1999) The glial scar and the central nervous system repair. Brain Res Bull 49:377-391.

Frisen J, Johansson CB, Torok C, Risling M, Lendahl U (1995) Rapid, widespread, and longlasting induction of nestin contributes to the generation of glial scar tissue after CNS injury. J Cell Biol 131:453-464.

Fuchs E, Yang Y (1999) Crossroads on cytoskeletal highways. Cell 98:547-550.

Ghirnikar RS, Yu AC, Eng LF (1994) Astrogliosis in culture. III. Effect of recombinant retrovirus expressing antisense glial fibrillary acidic protein RNA. J Neurosci Res 38:376-385.

Giménez y Ribotta M, Rajaofetra N, Morin-Richaud C, Alonso G, Bochelen D, Sandillon F, Legrand A, Mersel M, Privat A (1995) Oxysterol (7 beta-hydroxycholesteryl-3-oleate) promotes serotonergic reinnervation in the lesioned rat spinal cord by reducing glial reaction. J Neurosci Res 41:79-95.

Giménez y Ribotta M, Langa F, Menet V, Privat A (2000) Comparative anatomy of the cerebellar cortex in mice lacking vimentin, GFAP, and both vimentin and GFAP. Glia 31:69-83.

Goldman RD (1971) The role of three cytoplasmic fibers in BHK-21 cell motility. I. Microtubules and the effects of colchicine. J Cell Biol 51:752-762.

Goldman RD, Goldman AE, Green KJ, Jones JC, Jones SM, Yang HY (1986) Intermediate filament networks: organization and possible functions of a diverse group of cytoskeletal elements. J Cell Sci Suppl 5:69-97. 
Goldman RD, Chou YH, Prahlad V, Yoon M (1999) Intermediate filaments: dynamic processes regulating their assembly, motility, and interactions with other cytoskeletal systems. FASEB J 2:S261-S265.

Hatten ME, Liem RK, Shelanski ML, Mason CA (1991) Astroglia in CNS injury. Glia 4:233-243.

Henderson CE (1996) Role of neurotrophic factors in neuronal development. Curr Opin Neurobiol 6:64-70.

Herrmann H, Aebi U (2000) Intermediate filaments and their associates: multi-talented structural elements specifying cytoarchitecture and cytodynamics. Curr Opin Cell Biol 12:79-90.

Hirsch S, Bähr M (1999) Immunocytochemical characterization of reactive optic nerve astrocytes and meningeal cells. Glia 26:36-46.

Hubbard B, Lazarides E (1979) Co-purification of actin and desmin from chicken smooth muscle and their co-polymerization in vitro to intermediate filaments. J Cell Biol 80:166-182.

Keilhauer G, Faissner A, Schachner M (1985) Differential inhibition of neurone-neurone, neurone-astrocyte and astrocyte-astrocyte adhesion by L1, L2 and N-CAM antibodies. Nature 316:728-730.

Klymkowsky MW (1999) Weaving a tangled web: the interconnected cytoskeleton. Nat Cell Biol 1:E121-E123.

Lazarides E (1982) Intermediate filaments: a chemically heterogenous, developmentally regulated class of proteins. Annu Rev Biochem 51:219-250.

Lendahl U, Zimmerman LB, McKay RD (1990) CNS stem cells express a new class of intermediate filament protein. Cell 60:585-595.

Le Roux PD, Reh TA (1994) Regional differences in glial-derived factors that promote dendritic outgrowth from mouse cortical neurons in vitro. J Neurosci 14:4639-4655.

Letourneau PC, Condic ML, Snow DM (1992) Extracellular matrix and neurite outgrowth. Curr Opin Genet Dev 2:625-634.

Liesi P, Dahl D, Vaheri A (1983) Laminin is produced by early rat astrocytes in primary culture. J Cell Biol 96:920-924.

Liesi P, Kirkwood T, Vaheri A (1986) Fibronectin is expressed by astrocytes cultured from embryonic and early postnatal rat brain. Exp Cell Res 163:175-185.

Marvin NJ, Dahlstrand J, Lendahl U, McKay RDG (1998) A rod end deletion in the intermediate filament protein Nestin alters its subcellular localization in neuroepithelial cells of transgenic mice. J Cell Sci 111:1951-1961

Matthiessen HP, Schmalenbach C, Muller HW (1989) Astrogliareleased neurite growth-inducing activity for embryonic hippocampal neurons is associated with laminin bound in a sulfated complex and free fibronectin. Glia 2:177-188.

McKeon RJ, Schreiber RC, Rudge JS, Silver J (1991) Reduction of neurite outgrowth in a model of glial scarring following CNS injury is correlated with the expression of inhibitory molecules on reactive astrocytes. J Neurosci 11:3398-3411.

McKeon RJ, Höke A, Silver J (1995) Injury-induced proteoglycans inhibit the potential for laminin-mediated axon growth on astrocytic scars. Exp Neurol 136:32-43.

Menet V, Giménez y Ribotta M, Sandillon F, Privat A (2000) GFAP null astrocytes are a favorable substrate for neuronal survival and neurite growth. Glia 31:267-272.

Neugebauer KM, Tomaselli KJ, Lilien J, Reichardt LF (1988) $\mathrm{N}$-cadherin, NCAM, and integrins promote retinal neurite outgrowth on astrocytes in vitro. J Cell Biol 107:1177-1187.

Noble M, Fok-Seang J, Cohen J (1984) Glia are a unique substrate for the in vitro growth of central nervous system neurons. J Neurosci 4:1892-1903.

Noble M, Albrechtsen M, Moller C, Lyles J, Bock E, Goridis C, Watanabe M, Rutishauser U (1985) Glial cells express N-CAM/D2-CAM-like polypeptides in vitro. Nature 316:725-728.

Pekny M, Leveen P, Pekna M, Eliasson C, Berthold CH, Westermark B, Betsholtz C (1995) Mice lacking glial fibrillary acidic protein display astrocytes devoid of intermediate filaments but develop and reproduce normally. EMBO J 14:1590-1598.

Pekny M, Johansson CB, Eliasson C, Stakeberg J, Wallen A, Perlmann T, Lendahl U, Betsholtz C, Berthold CH, Frisen J (1999) Abnormal reaction to central nervous system injury in mice lacking glial fibrillary acidic protein and vimentin. J Cell Biol 145:503-514.

Pollerberg GE, Burridge K, Krebs KE, Goodman SR, Schachner M (1987) The $180-\mathrm{kD}$ component of neural cell adhesion molecule $\mathrm{N}-\mathrm{CAM}$ is involved in cell-cell contacts and cytoskeleton-membrane interactions. Cell Tissue Res 250:227-236.

Price J, Hynes RO (1985) Astrocytes in culture synthesize and secrete a variant form of fibronectin. J Neurosci 5:2205-2211.

Privat A (1975) Postnatal gliogenesis in the mammalian brain. In: Inter- national review of cytology, Vol 40 (Bourne GH, Danielli JF, eds), pp 281-323. New York: Academic.

Privat A, Giménez y Ribotta M, Ridet JL (1995) Morphology of astrocytes. In: Neuroglia, pp 3-22. New York: Oxford UP.

Qian J, Bulu MS, Levitt P (1992) Target-derived astroglia regulate axonal outgrowth in a region-specific manner. Dev Biol 149:278-294.

Rakic P (1971) Neuron-glia relationship during granule cell migration in developing cerebellar cortex. A Golgi and electron microscopic study in Macacus rhesus. J Comp Neurol 141:283-312.

Ramon y Cajal S (1913-1914) Estudios sobre la degeneracion y regeneracion del sisterna nervioso. Madrid: Moya.

Redies C (2000) Cadherins in the central nervous system. Prog Neurobiol 61:611-648.

Reichardt LF, Tomaselli KJ (1991) Extracellular matrix molecules and their receptors: functions in neural development. Annu Rev Neurosci $14: 531-570$

Reier PJ, Eng LF, Jakeman L (1989) Reactive astrocyte and axonal outgrowth in the injured CNS: is gliosis really an impediment to regeneration? In: Neural regeneration and transplantation, frontiers of clinical neuroscience, Vol 6 (Seil FJ, ed), pp 183-209. New York: Alan R. Liss.

Ridet JL, Malhotra SK, Privat A, Gage FH (1997) Reactive astrocytes: cellular and molecular cues to biological function. Trends Neurosci 20:570-577

Safell JL, Doherty P, Tiveron MC, Morris RJ, Walsh FS (1995) NCAM requires a cytoplasmic domain to function as a neurite outgrowthpromoting neuronal receptor. Mol Cell Neurosci 6:521-531.

Sanes JR (1989) Extracellular matrix molecules that influence neural development. Annu Rev Neurosci 12:491-516.

Schiffer D, Giordana MT, Migheli A, Giaccone G, Pezzotta S, Mauro A (1986) Glial fibrillary acidic protein and vimentin in the experimental glial reaction of the rat brain. Brain Res 374:110-118.

Schoenwaelder SM, Burridge K (1999) Bidirectional signaling between the cytoskeleton and integrins. Curr Opin Cell Biol 11:274-286.

Shaw G, Osborn M, Weber K (1981) An immunofluorescence microscopical study of the neurofilament triplet proteins, vimentin and glial fibrillary acidic protein within the adult rat brain. Eur J Cell Biol 26:68-82.

Sheppard AM, Hamilton SK, Pearlman AL (1991) Changes in the distribution of extracellular matrix components accompany early morphogenetic events of mammalian cortical development. J Neurosci 11:3928-3942.

Smith GM, Rutishauser U, Silver J, Miller RH (1990) Maturation of astrocytes in vitro alters the extent and molecular basis of neurite outgrowth. Dev Biol 138:377-390.

Smith GM, Jacobberger JW, Miller RH (1993) Modulation of adhesion molecule expression on rat cortical astrocytes during maturation. J Neurochem 60:1453-1466.

Tohyama T, Lee VM, Rorke LB, Marvin M, McKay RD, Trojanowski JQ (1992) Nestin expression in embryonic human neuroepithelium and in human. Lab Invest 66:303-313.

Tomaselli KJ, Neugebauer KM, Bixby JL, Lilien J, Reichardt LF (1988) $\mathrm{N}$-cadherin and integrins: two receptor systems that mediate neuronal process outgrowth on astrocyte surfaces. Neuron 1:33-43.

Trentin AG, Moura-Neto V (1995) T3 affects cerebellar astrocyte proliferation, GFAP and fibronectin organization. NeuroReport 6:293-296.

Vaughn JE, Peters A (1967) Electron microscopy of the early postnatal development of fibrous astrocytes. Am J Anat 121:131-152.

Wang X, Messing A, David S (1997) Axonal and non neuronal responses to spinal cord injury in mice lacking glial fibrillary acidic protein. Exp Neurol 148:568-576.

Weinstein DE, Shelanski ML, Liem RK (1991) Suppression by antisense mRNA demonstrates a requirement for the glial fibrillary acidic protein in the formation of stable astrocytic processes in response to neurons. J Cell Biol 112:1205-1213.

Yang HY, Lieska N, Goldman AE, Goldman RD (1992) Colchicinesensitive and colchicine-insensitive intermediate filament systems distinguished by a new intermediate filament-associated protein, IFAP70/280 kD. Cell Motil Cytoskeleton 22:185-199.

Yu AC, Lee YL, Eng LF (1991) Inhibition of GFAP synthesis by antisense RNA in astrocytes. J Neurosci Res 30:72-79.

Yu AC, Lee YL, Eng LF (1993) Astrogliosis in culture. I. The model and the effect of antisense oligonucleotides on glial fibrillary acidic protein synthesis. J Neurosci Res 34:295-303.

Zuo J, Neubauer D, Dyess K, Ferguson TA, Muir D (1998) Degradation of chondroitin sulfate proteoglycan enhances the neurite-promoting potential of spinal cord tissue. Exp Neurol 154:654-662. 